\title{
Mineralogical properties and internal structures of individual fine particles of Saharan dust
}

\author{
Gi Young Jeong ${ }^{1}$, Mi Yeon Park ${ }^{1}$, Konrad Kandler ${ }^{2}$, Timo Nousiainen ${ }^{3}$, and Osku Kemppinen ${ }^{3,4}$ \\ ${ }^{1}$ Department of Earth and Environmental Sciences, Andong National University, Andong 36729, Republic of Korea \\ ${ }^{2}$ Institut für Angewandte Geowissenschaften, Technische Universität Darmstadt, Schnittspahnstr. 9, \\ 64287 Darmstadt, Germany \\ ${ }^{3}$ Earth Observation, Finnish Meteorological Institute, P.O. Box 503, 00101, Helsinki, Finland \\ ${ }^{4}$ Department of Physics, Kansas State University, 116 Cardwell Hall, Manhattan, KS 66506, USA \\ Correspondence to: Gi Young Jeong (jearth@anu.ac.kr)
}

Received: 8 April 2016 - Published in Atmos. Chem. Phys. Discuss.: 15 April 2016

Revised: 14 September 2016 - Accepted: 21 September 2016 - Published: 4 October 2016

\begin{abstract}
Mineral dust interacts with incoming/outgoing radiation, gases, other aerosols, and clouds. The assessment of its optical and chemical impacts requires knowledge of the physical and chemical properties of bulk dust and single particles. Despite the existence of a large body of data from field measurements and laboratory analyses, the internal properties of single dust particles have not been defined precisely. Here, we report on the mineralogical organization and internal structures of individual fine $(<5 \mu \mathrm{m})$ Saharan dust particles sampled at Tenerife, Canary Islands. The bulk of Tenerife dust was composed of clay minerals ( $81 \%)$, followed by quartz (10\%), plagioclase (3\%), and K-feldspar $(2 \%)$. Cross-sectional slices of Saharan dust particles prepared by the focused ion beam technique were analyzed by transmission electron microscopy (TEM) to probe the particle interiors. TEM analysis showed that the most common particle type was clay-rich agglomerate, dominated by illite-smectite series clay minerals with subordinate kaolinite. Submicron grains of iron (hydr)oxides (goethite and hematite) were commonly dispersed through the clay-rich particles. The median total volume of the iron (hydr)oxide grains included in the dust particles was estimated to be about $1.5 \%$ vol. The average iron content of clay minerals, assuming $14 \mathrm{wt} \% \mathrm{H}_{2} \mathrm{O}$, was determined to be $5.0 \mathrm{wt} \%$. Coarse mineral cores, several micrometers in size, were coated with thin layers of clay-rich agglomerate. Overall, the dust particles were roughly ellipsoidal, with an average axial ratio of $1.4: 1.0: 0.5$. The mineralogical and structural properties of single Saharan dust particles provide a basis for the mod-
\end{abstract}

eling of dust radiative properties. Major iron-bearing minerals, such as illite-smectite series clay minerals and iron (hydr)oxides, were commonly submicron- to nano-sized, possibly enhancing their biogeochemical availability to remote marine ecosystems lacking micronutrients.

\section{Introduction}

Mineral dust affects Earth's climate and ecosystems via interaction with electromagnetic radiation (Sokolik and Toon, 1996; Tegen and Lacis, 1996; Formenti et al., 2011), acidic gases, and anthropogenic aerosols (Dentener et al., 1996; Ooki and Uematsu, 2005; Laskin et al., 2005); by becoming ice nuclei (Kulkarni and Dobbie, 2010; Freedman, 2015); and by delivering micronutrients to remote ocean and terrestrial environments (Swap et al., 1992; Mahowald et al., 2009; Johnson and Meskhidze, 2013). To understand the interactions of dust with environments, a wide range of studies have been carried out to characterize the physical and chemical properties of bulk dust and individual dust particles, such as the size distribution (Seinfeld et al., 2004), particle morphology (Okada et al., 2001; Reid et al., 2003), chemical composition (Coude-Gaussen, 1987; Okada et al., 1990; Kanayama et al., 2002; Ro et al., 2005; Klaver et al., 2011; Arimoto et al., 2004), and mineral composition (Glaccum and Prospero, 1980; Avila et al., 1997; Shi et al., 2005; Kandler et al., 2007, 2009; Jeong, 2008; Shao et al., 2008; Jeong et al., 2014). 
Of these properties, the internal structure and mineralogical properties of individual dust particles have been the least studied, largely due to the lack of suitable and reliable methods. Scanning electron microscopy (SEM) combined with energy-dispersive X-ray spectrometry (EDXS) has been applied to obtain information on the two-dimensional (2-D) morphology and overall chemical composition of individual particles (Okada et al., 1990; Anderson et al., 1996; Ro et al., 2005; Gao et al., 2007). These individual dust particles, however, are usually composed of polymineralic/polycrystalline mixtures of diverse minerals (Falkovich et al., 2001; Jeong, 2008), and SEM-EDXS cannot easily yield information on their internal structures and mineralogical properties. The focused ion beam (FIB) technique was applied to expose the cross sections of urban dust particles for SEM analysis (Conny, 2013). A practical method for the acquisition of data on the internal properties, however, was transmission electron microscopy (TEM) for thin cross-sectional slices prepared from single dust particles by the FIB technique. With these improvements, Jeong and Nousiainen (2014) reported internal structures and mineralogical makeup of single particles of Asian dust which could be classified into several structural types.

Knowledge of the internal properties of dust particles is essential for the establishment of a realistic model of mineral dust, which would enable assessment of its radiative properties and biogeochemical contributions. Based on the findings by Jeong and Nousiainen (2014), Kemppinen et al. (2015) calculated the optical properties of internally inhomogeneous single dust particles and showed that their light scattering properties depended significantly on their internal structures and iron oxide mineralogy of dust particles, as well as how they were accounted for in the modeling. The difficulty of accurately mimicking the impacts of these inhomogeneities on scattering by effective medium approximations suggests that accurate optical models of dust particles should account explicitly for at least the most impactful types of internal inhomogeneity. Regarding biogeochemical contributions, mineral dust transported to remote marine ecosystems is reportedly responsible for phytoplankton blooms due to the supply of iron, and terrestrial ecosystems are also considerably impacted (Swap et al., 1992; Boyd et al., 2000; Jickells et al., 2005; Formenti et al., 2011). The bioavailability of iron in oceans depends largely on its mineralogical form in the dust particles (Cwiertny et al., 2008; Journet et al., 2008), which can also be investigated on FIB slices using TEM.

The Sahara is the largest single source of atmospheric dust. Large volumes of this emitted dust are transported over long distances across the Atlantic Ocean and Mediterranean Sea. Although the physical, chemical, and mineralogical properties of bulk Saharan dust and single particles have been investigated (Falkovich et al., 2001; Reid et al., 2003; Kandler et al., 2007, 2009; Formenti et al., 2011), the mineralogical compositions and structures of dust particle interiors have not been studied. Jeong and Achterberg (2014) attempted TEM

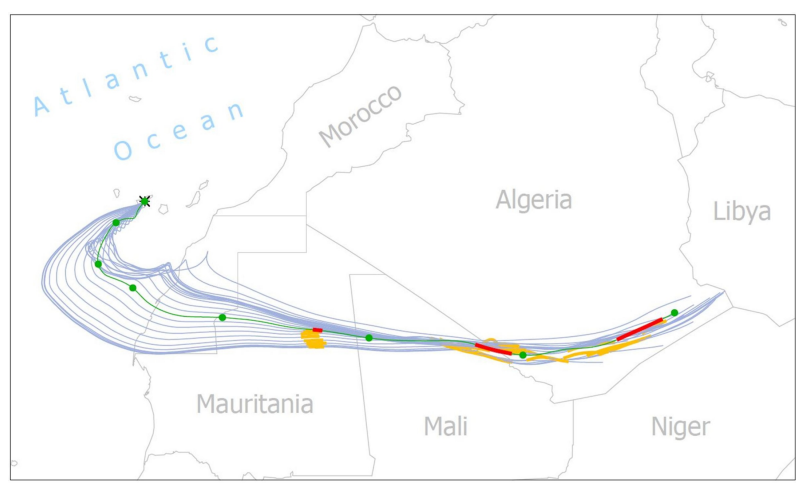

Figure 1. Map of northwestern Africa with the hourly $168 \mathrm{~h}$ backward trajectory evolution, which shows dust arriving at Izaña ( $2400 \mathrm{~m}$ a.s.1.) on 16 July 2005 . Green trajectories represent the impactor sample. The filled circles indicate $24 \mathrm{~h}$ periods. Trajectory sections where the altitude is below the mixing layer height are enhanced in orange/red.

analysis of FIB slices prepared from individual Saharan dust particles, but unsuccessfully as original individual dust particles could not be identified on their filter heavily deposited with dust. To extend the mineralogical and structural analyses of Asian dust particles conducted by Jeong and Nousiainen (2014), we have now conducted a similar analysis of FIB slices prepared from fine Saharan dust particles collected specifically for single-particle electron microscopic analysis.

\section{Samples and methods}

Dust samples used in this study collected from the top of the tower building of the meteorological observatory of Izaña, Tenerife, Spain $\left(28^{\circ} 18^{\prime} 33.8^{\prime \prime} \mathrm{N}, 16^{\circ} 29^{\prime} 56.9^{\prime \prime} \mathrm{W}\right.$; $2395 \mathrm{~m}$ a.s.1.). Details on the procedure and location can be found in Kandler et al. (2007). Particles were collected with a cascade impactor on carbon adhesive, with nominal stage size ranges of $>2.6,0.9-2.6$, and $0.1-0.9 \mu \mathrm{m}$ (50\% efficiency cut-off aerodynamical particle diameter), of which the stages with $>0.9 \mu \mathrm{m}$ were used for analysis. All samples were stored in a desiccator under dry conditions prior to analysis. The sample analyzed in the present work was collected during a 10 min period on 15 July 2005 at 09:33 (UTC). It was selected as best representing the campaign to achieve the greatest atmospheric relevance. Its composition is close to the mean campaign composition (see Kandler et al., 2007, Fig. 8), and the corresponding transport trajectory is central in the observed trajectory field (Fig. 1 and Kandler et al., 2007, Fig. 9). According to AERONET aerosol optical thickness data (Supplement Fig. S1), the concentration on the sampling day was also close to the average of the dust event lasting from 12 to 22 July 2005. Analysis was limited to particles with diameter $<5 \mu \mathrm{m}$, as too few larger ones were available. 
Backward trajectories of air mass were calculated by HYSPLIT4 rev. 16 June 2015 (Stein et al., 2015). Figure 1 shows the trajectory plots for the impactor sample. The atmospheric circulation on the sampling day was stable, with a continuous flow leaving the western part of the Sahara at altitudes of 3-4 km and traveling over the ocean during the final 2 days before arrival under very dry conditions (10-30\% relative humidity). Dust injection is assumed for parts of the trajectory, which were inside the modeled mixing layer. Northeastern Mauritania and southern Algeria are the most probable source regions for the analyzed sample. According to the trajectory analysis, the injected dust had traveled for a minimum of 4 days before it was collected at Izaña. Due to the dry conditions, however, considerable alteration of the dust components was not expected.

Dust particles were analyzed using a TESCAN LYRA3 $\mathrm{XMH}$ field emission scanning electron microscope equipped with a Bruker EDXS system. SEM images showed that the individual particles were sufficiently separated from each other, with no coagulation occurring during deposition. All the particles collected on the impact stages were not analyzed. We selected rectangular areas of homogeneous particle distribution at low magnification, and then EDXS patterns were obtained from all the particles in the areas. The total number of the analyzed dust particles was 1626:1191 particles from the impact stage $0.9-2.6 \mu \mathrm{m}$ and 435 particles from the stage $>2.6 \mu \mathrm{m}$. EDXS patterns were classified according to predominant mineral to obtain approximate mineral compositions of bulk dust (Supplement; Jeong, 2008; Jeong et al., 2014). The mineral composition obtained by this method is evidently semi-quantitative, considering large inherent uncertainty. Previous analyses of Asian dust, however, showed that SEM-EDXS results were consistent with XRD results (Park and Jeong, 2016). The 48 target particles for FIB work were selected according to the mineralogical types of the dust particles, reflecting mineral abundance of bulk dust determined by EDXS analyses: 21 particles from the impact stage $0.9-2.6 \mu \mathrm{m}$ and 27 particles from the impact stage $>2.6 \mu \mathrm{m}$, respectively. Thus, the 48 FIB slices analyzed are representative of the Saharan dust particles collected on the sampler. However, three iron-enriched particles were selected for the identification of iron (hydr)oxide mineral species, which were not common.

Dust particles on the carbon adhesive were placed in a JEOL JIB-4601F FIB instrument to prepare thin crosssectional slices (ca. $6 \mu \mathrm{m} \times 6 \mu \mathrm{m},<100 \mathrm{~nm}$ thickness). Detailed procedures of slice preparation using FIB techniques and a discussion of possible artifacts were provided in Jeong and Nousiainen (2014). The slices are cross sections along the shorter axes of the particles observed by SEM. A total of 48 FIB slices were prepared from 48 dust particles and analyzed using a JEOL JEM 3010 transmission electron microscope for lattice-fringe imaging and a JEOL JEM 2010 transmission electron microscope equipped with an Oxford $\mathrm{X}$-MAX EDXS system for internal-structure imaging and chemical analysis. TEM images of 18 slices are presented here, and those of 30 slices are presented in Supplement Fig. S2.

Minerals in the FIB slices were identified by the combined use of EDXS, electron diffraction, and lattice-fringe imaging. The identification criteria for minerals are summarized in the Supplement. Nano-thin platelets of illite-smectite series clay minerals (ISCMs) have been found commonly in TEM analyses of natural mineral dusts (Jeong et al., 2014; Jeong and Nousiainen, 2014; Jeong and Achterberg, 2014). They are nano-scale mixtures of nano-thin platelets of illite, smectite, and illite-smectite mixed layer clay minerals, all of which have lattice fringes measuring $\sim 1.0 \mathrm{~nm}$ due to the dehydration of smectite interlayer water. Despite the differences in their chemical compositions, the routine identification of these minerals using TEM-EDXS is challenging because the electron beam diameter could not be reduced below $\sim 100 \mathrm{~nm}$ without severe beam damage and count loss. Thus, to avoid over-interpretation of TEM data, nano-thin platelets of clay minerals showing $\sim 1 \mathrm{~nm}$ lattice fringes with varying contents of interlayer $\mathrm{K}$ and $\mathrm{Ca}$ were grouped as ISCMs (Jeong and Nousiainen, 2014). In some cases, when the separate chemical identification of illite and smectite platelets was possible due to the large grain size, we used the terms illite and smectite.

The mineralogical identification of iron (hydr)oxide polymorphs was performed using electron diffraction and latticefringe imaging. The routine unambiguous identification of all iron (hydr)oxide grains, however, was challenging due to the superimposition of d-spacings, varying crystallographic orientations, and often vague electron diffraction patterns. Thus, we used mineralogical names only in cases in which mineral species were identified unambiguously by lattice-fringe imaging and electron diffraction; in other cases, we used the collective term "iron (hydr)oxide". Chemical compositions of ISCMs, illite, smectite, chlorite, and biotite were quantified by measuring X-ray intensities of $\mathrm{Si}, \mathrm{Al}, \mathrm{Fe}, \mathrm{Mg}, \mathrm{Ti}, \mathrm{K}$, $\mathrm{Na}$, and $\mathrm{Ca}$. The X-ray counts of the elements were converted to weight $\%$ using $k$ factors determined experimentally from FIB slices of biotite and plagioclase of known composition from the Palgongsan granite (Jeong, 2000). More details can be found in Jeong and Achterberg (2014), except that this study used a more sensitive Oxford X-MAX EDXS detector. In this study, the term "particle" refers to an individual airborne solid object and the term "grain" refers to a particle constituent. In most cases, particles were agglomerates of grains.

\section{Results and discussion}

\subsection{Mineral composition of bulk dust}

Single-particle SEM-EDXS data showed that dust particles in both size fractions were dominated by clay minerals in- 

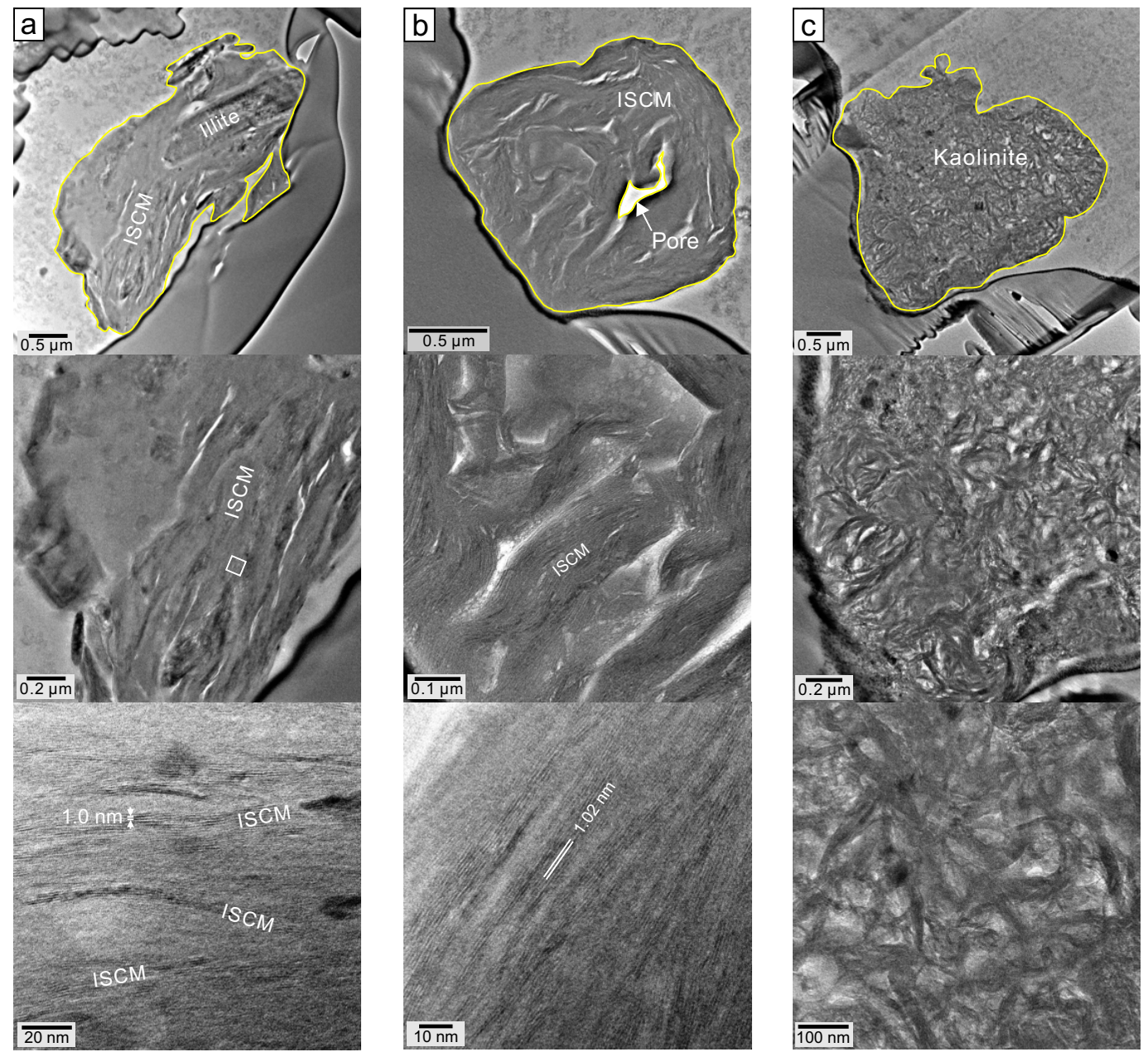

Figure 2. TEM images of cross sections of clay-rich dust particles. ISCM: illite-smectite series clay minerals, including illite, smectite, and their mixed layers. (a) ISCM clays, including an illite grain (particle 30). (b) ISCM clay (particle 48). (c) Kaolinite (particle 40). Yellow lines were added to show the boundary of particle and pore.

cluding ISCMs and kaolinite. Dust particles of 0.9-2.6 $\mu \mathrm{m}$ in size, however, were slightly enriched in clay minerals in comparison with those of $>2.6 \mu \mathrm{m}$ in size, while nonclay minerals including quartz, plagioclase, and K-feldspar were rather enriched in coarser particles $(>2.6 \mu \mathrm{m})$. Average mineral composition was ISCMs $69 \%$, kaolinite $11 \%$, quartz $10 \%$, plagioclase $3 \%$, K-feldspar $2 \%$, calcite $1 \%$, chlorite $1 \%$, iron (hydr)oxide $1 \%$, titanium oxide $1 \%$, and gypsum $1 \%$ (Table 1 ). The total clay mineral content was $81 \%$. Scheuvens et al. (2013) have proposed a $\mathrm{Ca} / \mathrm{Fe}$ ratio for source discrimination of Saharan dust, with very low $\mathrm{Ca} / \mathrm{Fe}$ ratios for the probable regions. The very low calcite content of the Tenerife Saharan dust sample is thus in agreement with the identification of source regions by backward trajectory analysis.

\subsection{Internal structures of individual dust particles}

\subsubsection{Clay-rich particles}

Clay-rich particles were the most common (Fig. 2). They were dominated by ISCMs, which were loose, sub-parallel agglomerates of slightly curved nano-thin platelets with $1.0 \mathrm{~nm}$ lattice fringes (Fig. 2a). The morphological features of ISCMs contrasted with those of illite, which were thick, straight, and compact (Fig. 2a). Very few clay-rich particles were pure ISCMs (Fig. 2b) or kaolinite (Fig. 2c). They were commonly mixtures with dominant ISCMs and subordinate kaolinite.

\subsubsection{Large minerals with clay-rich coatings}

Large mineral grains, such as quartz, plagioclase, and Kfeldspar, were usually coated with thin clay layers composed of ISCMs and kaolinite. The large core grains were roughly 

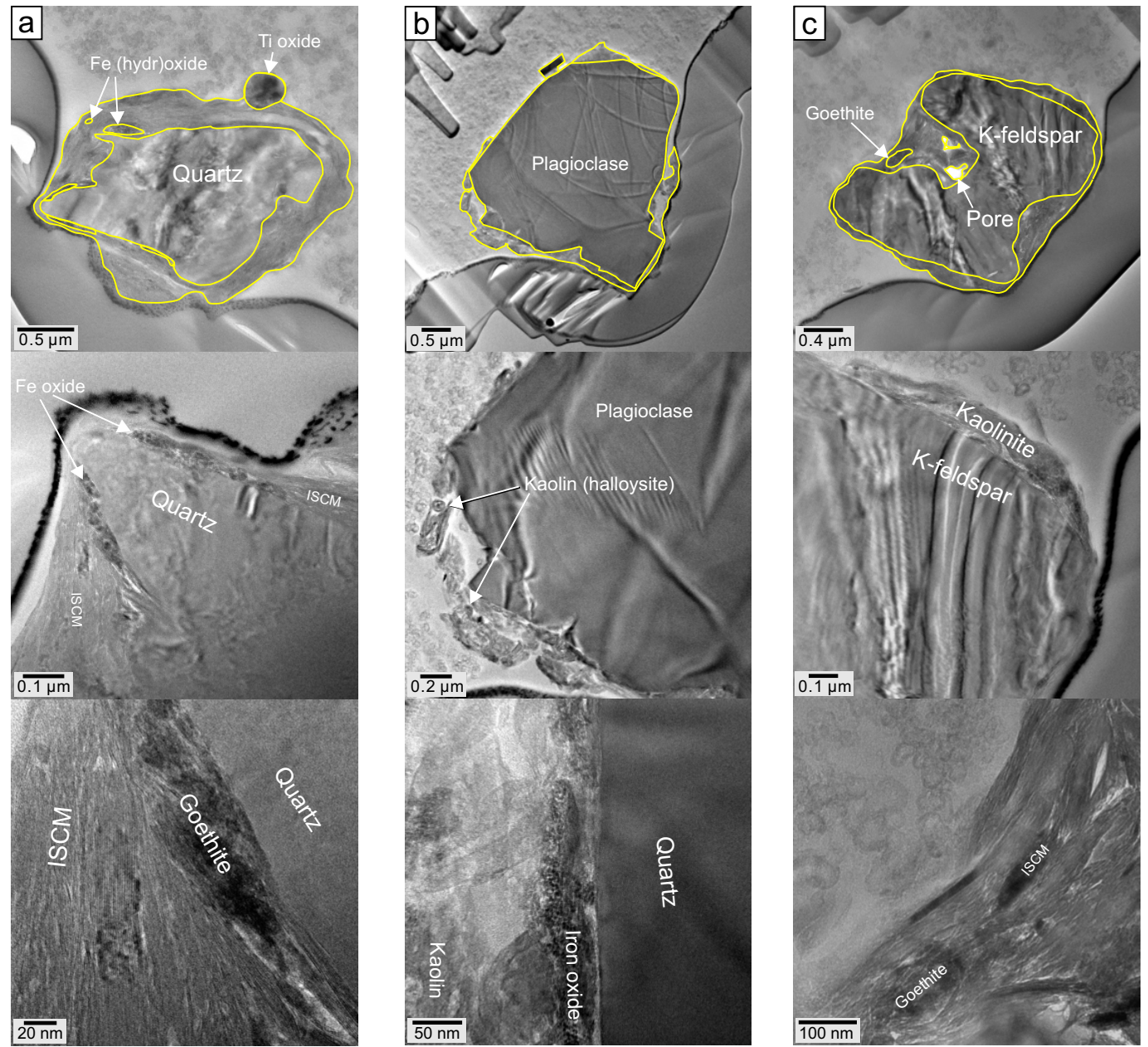

Figure 3. TEM images of cross sections of large grains coated with clays. (a) Quartz grain coated with clays (particle 46). (b) Plagioclase grain coated with clays (particle 37). (c) K-feldspar grain coated with clays (particle 28). Yellow lines were added to show particle boundary and the interface between clay coating and substrate.

equidimensional, with irregular surfaces (Fig. 3). The thicknesses of the clay coatings varied due to the irregular surface topographies of the substrates. Our observations confirmed a near absence of clean surfaces free of clay coatings on quartz, plagioclase, and K-feldspar. Large phyllosilicate grains, such as illite, biotite, and chlorite, were plates with smooth surfaces coated with clays (Fig. 4). Submicron grains of iron oxides were found at the interfaces between clay coatings and substrates (Fig. 3a, b) or scattered through the clay coatings (Fig. 4c).

\subsubsection{Intergrade particles}

Some dust particles were intergrades between clay-rich particles and clay-coated minerals. The intergrade particles were composed of abundant clays with large mineral inclusions of K-feldspar (Fig. 5a), dolomite (Fig. 5b), and calcite (Fig. 5c), as well as quartz, plagioclase, and large phyllosilicates such as biotite, chlorite, and illite (Supplement Fig. S2). Clays consisted mostly of ISCMs and kaolinite with submicron grains of iron (hydr)oxides. The clay matrices of the intergrade particles shown in Fig. 5b and c included palygorskite fibers.

\subsection{Iron (hydr)oxides}

Dust particles dominated by iron (hydr)oxides were rare (Fig. 6). Most iron (hydr)oxides occurred as submicron grains dispersed in the clay matrices of clay-rich particles (Fig. 7). Although the absolute content of iron (hydr)oxides in mineral dust is small (Lafon et al., 2006; Jeong, 2008; Jeong et al., 2014; Journet et al., 2014), the role of these components in light scattering deserves attention due to their high refractive index/absorption (Sokolik and Toon, 1999; Lafon et al., 2006; Kemppinen et al., 2015). The species, volume \%, grain size, and distribution of iron (hydr)oxides in the interiors of dust particles therefore must be considered in the modeling of optical properties. 

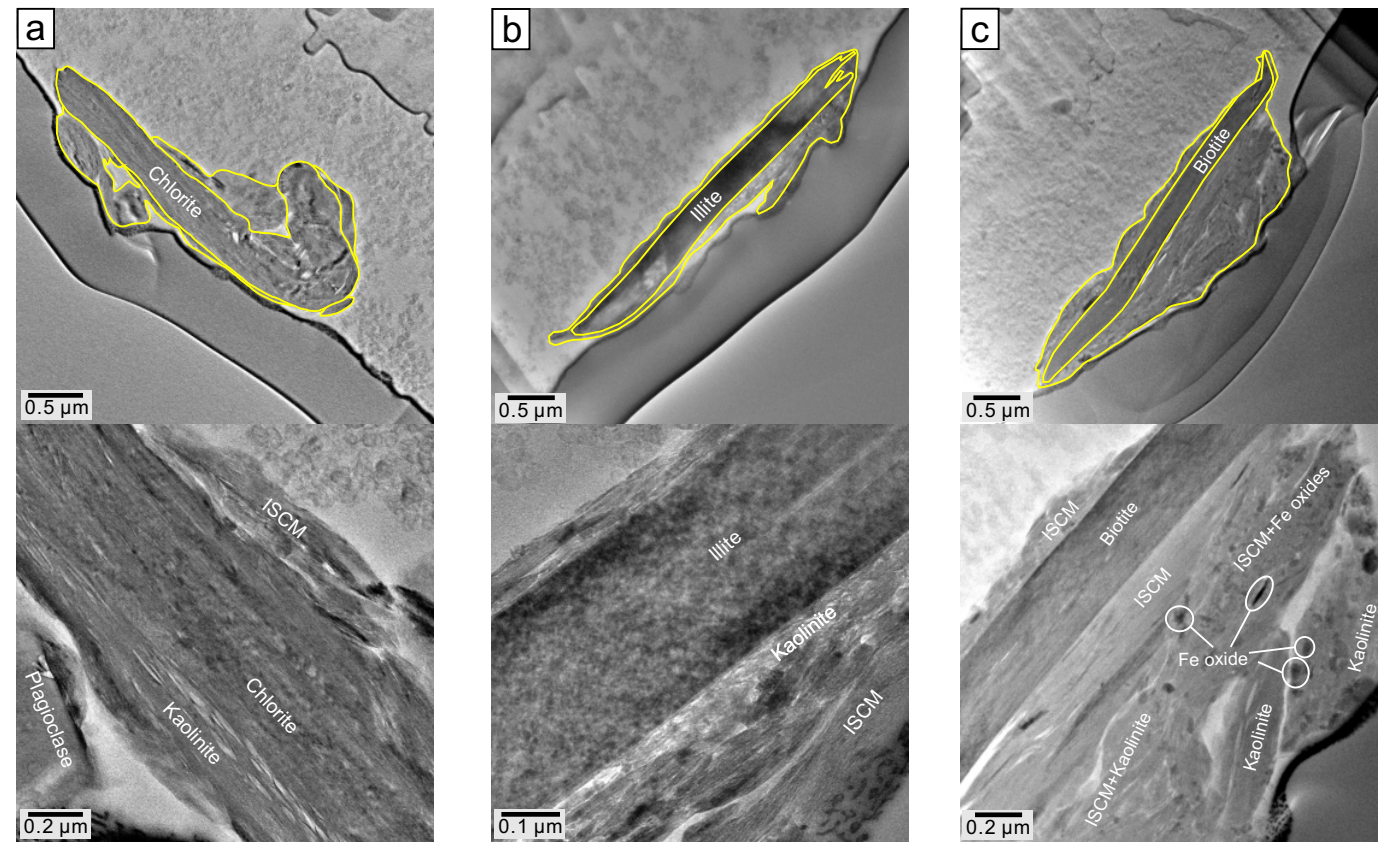

Figure 4. TEM images of cross sections of large platy grains coated with clays. (a) Chlorite plate coated with ISCM and kaolinite clays (particle 41). (b) Illite plate coated with ISCM and kaolinite clays (particle 34). (c) Biotite plate coated with ISCM and kaolinite clays (particle 23). Yellow lines were added to show particle boundary and the interface between clay coating and substrate.

The mineral species of iron (hydr)oxides identified by electron diffraction and lattice fringes were goethite (Fig. 7a, c, d) and hematite (Fig. 7a, b, e). We could not estimate the relative proportions of goethite and hematite quantitatively because the identification of iron (hydr)oxides was not a routine procedure. Qualitatively, however, goethite grains were likely more common than hematite, similar to the findings of Lafon et al. (2006). Iron (hydr)oxides were included in 40 of the 48 FIB slices. Goethite was positively identified by electron diffraction and lattice imaging in 19 slices, hematite was identified in eight slices, and magnetite was identified in two slices.

We estimated the total volume\% of iron (hydr)oxide grains in a dust particle from their area \% measured in brightfield TEM images using the lasso tool and histogram of Adobe Photoshop CS5, as these minerals occur as dark grains due to their high atomic numbers. However, we could not perform grain-by-grain identification or measurement of the numerous iron (hydr)oxide grains, as discussed in Sect. 2. Although the third dimension could not be measured, the measured area $\%$ of iron (hydr)oxide grains approximates their total volume $\%$ because the relatively small iron (hydr)oxide grains were homogeneously distributed through the dust particles (Vepraskas and Wilson, 2008). The abundance of iron (hydr)oxide grains ranged widely, from high (e.g., $50 \%$ in Fig. 7a, $28 \%$ Fig. 7 e) to moderate (e.g., $15 \%$ Fig. 7b, $9 \%$ Fig. 7c), sparse (e.g., $3 \%$ Figs. $2 \mathrm{c}$ and $7 \mathrm{~d}, 0.7 \%$ Fig. 3c), and absent (e.g., Fig. 2a and b). The median volume of iron (hydr)oxides in 48 dust particles was $1.5 \%$. Half of the values fell between 1 and 10\% (Supplement Table S1). Some of the dark grains in the TEM images were titanium oxides (Fig. 7b), although their contents were lower than those of iron (hydr)oxides in most particles. Thus, the measured volume $\%$ of iron (hydr)oxides must be considered a maximum value, as we could not account for the titanium oxides explicitly.

Grain sizes of iron (hydr)oxides ranged from a few hundred to several tens of nanometers. All longer axes of iron (hydr)oxide grains in the interiors of dust particles fell within the submicron range; most were $<0.5 \mu \mathrm{m}$ with common small grains of several tens of nanometers long (Fig. 7). The grains were well dispersed throughout the clay-rich medium, in contrast to the findings of Deboudt et al. (2012), who detected them more commonly on the surface.

\subsection{Chemical composition of clay minerals}

The chemical compositions of clay minerals from the Tenerife dust particles, determined by TEM-EDXS of FIB slices, were plotted on a $\mathrm{K}-\mathrm{Fe}$ diagram (Fig. 8). The data distribution was consistent with that for Saharan dust collected in Cape Verde (Fig. 6 in Jeong and Achterberg, 2014). Almost all data plotted between ISCMs and kaolinite, confirming the higher kaolinite content of Saharan dust. The average elemental composition of clay minerals, based on 343 EDXS analyses and assuming $14 \mathrm{wt} \% \mathrm{H}_{2} \mathrm{O}$, was $22.4 \mathrm{wt} \%$ $\mathrm{Si}, 13.2 \mathrm{wt} \% \mathrm{Al}, 5.0 \mathrm{wt} \% \mathrm{Fe}, 1.8 \mathrm{wt} \% \mathrm{Mg}, 0.2 \mathrm{wt} \% \mathrm{Ti}$, 

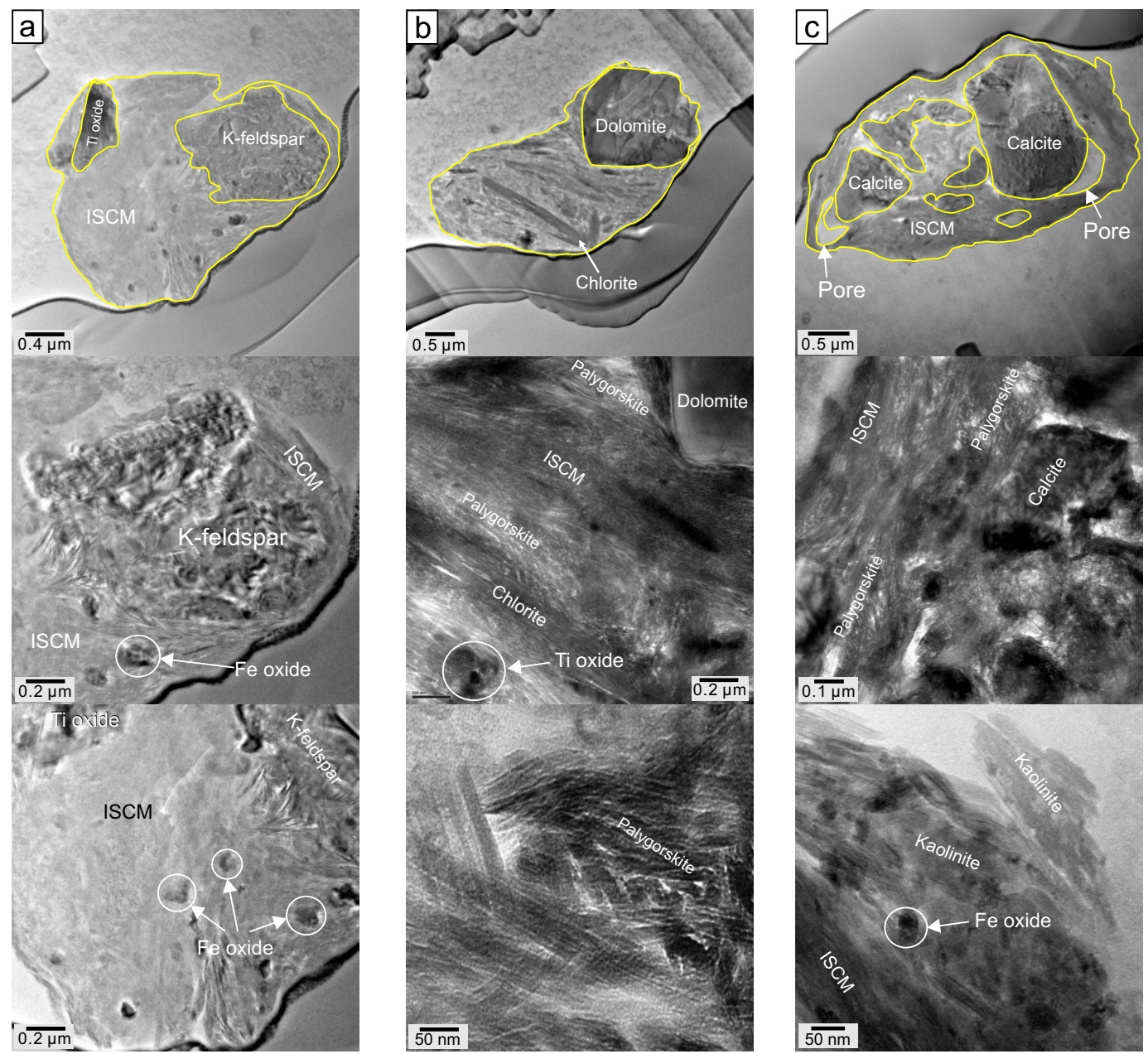

Figure 5. TEM images of cross sections of particles composed of clay and non-clay mineral inclusions. (a) K-feldspar and titanium oxide grains agglomerated with ISCM clay (particle 27). (b) Dolomite and chlorite grains agglomerated with ISCM and palygorskite clays (particle 26). (c) Calcite grains agglomerated with ISCM and palygorskite clays (particle 29). Yellow lines were added to show the boundary of particle and pore and the interface between clay and large mineral inclusion.
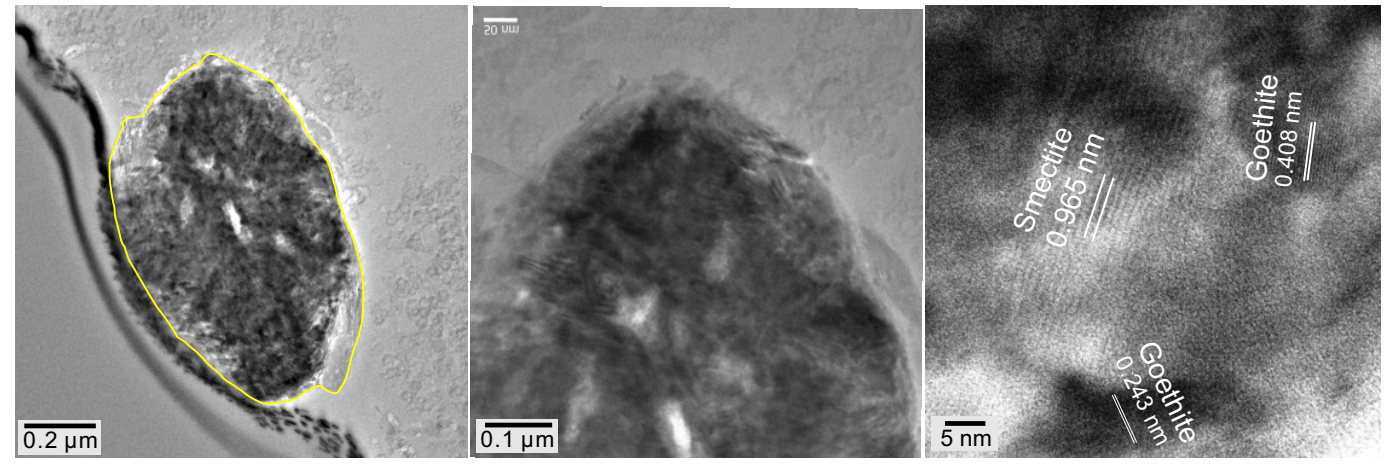

Figure 6. TEM images of a cross section of the iron (hydr)oxide (goethite) particle (particle 14). Yellow line was added to show particle boundary. 

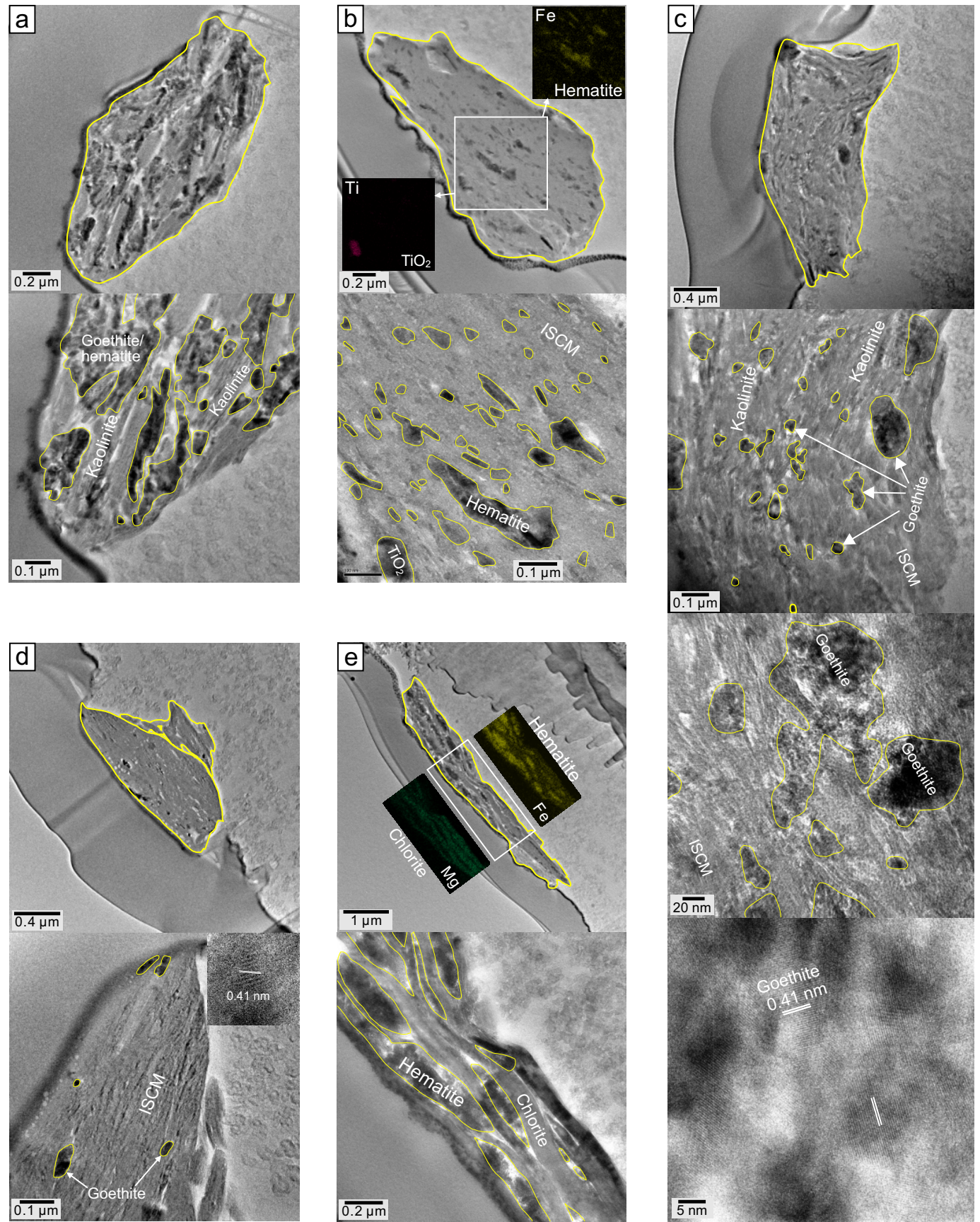

Figure 7. TEM images of cross sections of clay particles containing rich iron (hydr)oxide grains. (a) Mixture of iron (hydr)oxides (goethite and hematite) and kaolinite clay (particle 3). (b) ISCM clay including elongated hematite grains of varying sizes, showing preferred orientation with some titanium oxide grains (particle 43). (c) ISCM-kaolinite clay interspersed with goethite grains of varying sizes (particle 11). (d) ISCM clay including several grains of goethite (particle 21). (e) Platy grains of weathered chlorite showing hematite grains in the cleaved spaces between curved chlorite plates (particle 45). Insets in (b, e) are X-ray maps.

$1.2 \mathrm{wt} \% \mathrm{~K}, 0.5 \mathrm{wt} \% \mathrm{Na}$, and $0.4 \mathrm{wt} \% \mathrm{Ca}$. The average iron content $(5.0 \%)$ of the clay minerals in the Tenerife dust is consistent with that of the clay minerals in Cape Verde dust. The chemical compositions of ISCMs are plotted in the boxed region of Fig. 8, as derived in Jeong and Achter- berg (2014). The average chemical formula of the Saharan dust ISCMs was $\mathrm{K}_{0.17} \mathrm{Na}_{0.09} \mathrm{Ca}_{0.03}\left(\mathrm{Al}_{1.43} \mathrm{Fe}_{0.38}^{3+} \mathrm{Mg}_{0.36}\right.$ $\left.\mathrm{Ti}_{0.01}\right)\left(\mathrm{Al}_{0.50} \mathrm{Si}_{3.50}\right) \mathrm{O}_{10}(\mathrm{OH})_{2}$. 


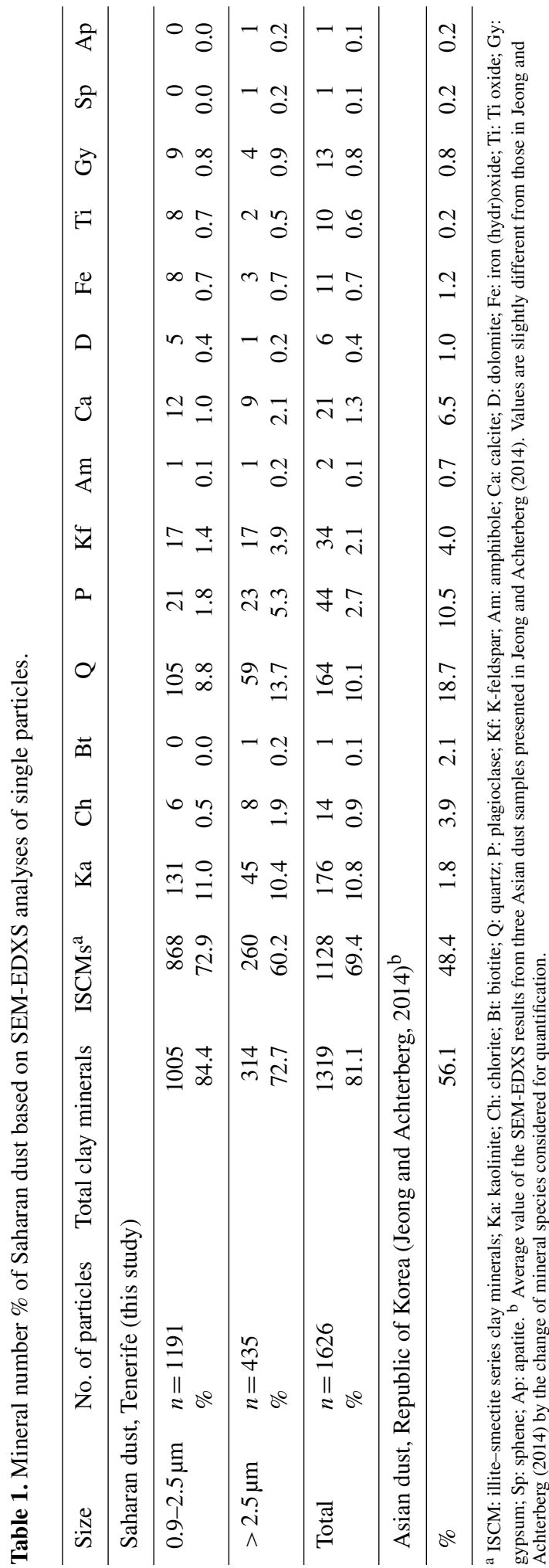

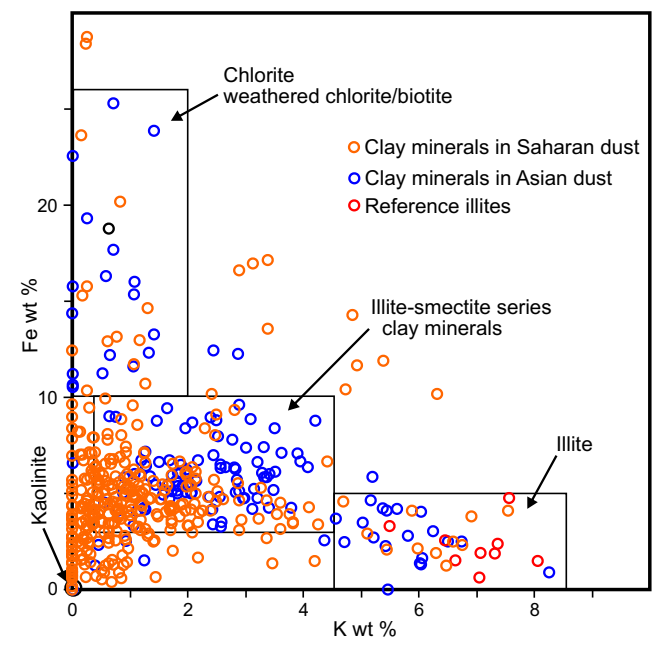

Figure 8. Plots of Fe vs. K from the TEM-EDXS analyses of clay minerals in the FIB slices of dust particles. The boxes indicating groups $\mathrm{A}, \mathrm{B}$, and $\mathrm{C}$ are drawn based on TEM microtextures and EDXS data provided by Jeong and Achterberg (2014).

\subsection{Shape of dust particles}

The 2-D shapes of dust particles have been approximated by ellipses with varying aspect ratios (e.g., Reid et al., 2003). Although the three-dimensional (3-D) shapes of the particles resemble ellipsoids, they are - due to the lack of information on the third dimension - usually assumed to be spheroids in particle size analyses (Reid et al., 2003; Kandler et al., 2009; Jeong et al., 2014) and in optical modeling (Mishchenko et al., 1997; Nousiainen and Vermeulen, 2003; Dubovik et al., 2006; Merikallio et al., 2011). As a byproduct of FIB work on studies of dust interiors, the thicknesses of the particles can be derived from TEM images of the cross sections (Fig. 9). The two longer axes ( $b$ and $c$ ) of the ellipsoids were measured from SEM images, and the short axis $(a)$ was measured from TEM cross-section images. The average axial ratios of 48 particles, obtained by dividing the lengths of axes $a$ and $c$ by that of axis $b$, were $1.4 \pm 0.3(c / b)$ and $0.5 \pm 0.3(a / b)$, respectively (Supplement Table S1). The axial ratios of ellipsoids varied slightly, depending on the major mineral components of the particles. The $a / b$ ratios were highly dependent on the mineralogical types of the particles; the average of this ratio was 0.5 in clay-rich particles; 0.7 in quartz, plagioclase, and K-feldspar with clay coatings; and 0.2 in particles consisting of coarse platy phyllosilicate minerals with clay coatings (Supplement Table S1). The average of $c / b$ ratio was 1.3 in clay-rich particles and $\sim 1.5$ in coarse minerals with coatings. 


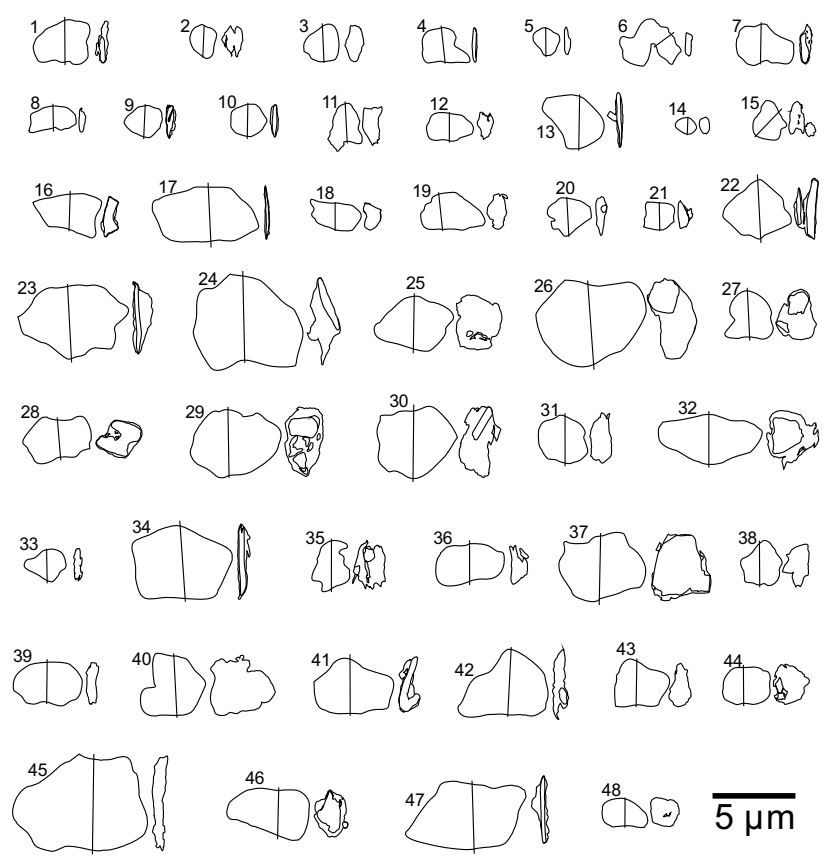

Figure 9. External shapes of 48 dust particles investigated in this study. The left-hand sketch of each particle denotes particle outlines observed in the vertical direction by SEM. Two longer axes of dust particle ellipsoids lie parallel to the substrate carbon tape. Rightside sketch denotes particle outline observed in the cross section cut along the straight line of the left-hand sketch.

\subsection{Comparison with single-particle properties of Asian dust}

The clay content of Saharan dust (81\%) is higher than that of Asian dust (57\%) (Table 1). Previous data showed that total clay content of Saharan dust ranged from 61 to $73 \%$ in the samples of the Atlantic islands (Glaccum and Prospero, 1980), from 56 to $81 \%$ in the dustfall collected in Spain (Avila et al., 1997), and around $81 \%$ in two Saharan dust samples collected in Cape Verde (Jeong and Achterberg, 2014). Total clay content of Asian dust ranged from 28 to $50 \%$ in Beijing, China (Shao et al., 2008), and around $57 \%$ in the Republic of Korea (Jeong and Achterberg, 2014). Thus, clay minerals are likely enriched in Saharan dust in comparison with Asian dust. Mineral compositions of clays also differ slightly between dusts. The analyzed Saharan dust sample is distinct from Asian dust due to its higher kaolinite content and lower chlorite content. The average Fe wt \% of the clay minerals in Asian dust was $6.7 \%$, which was slightly higher than that for Saharan dust (5\%). The lower iron content of Saharan dust clay minerals is consistent with the lower chlorite content and the higher kaolinite content. ISCMs are the major mineral components of both Saharan and Asian dusts. Assuming $\mathrm{K}$ fixation in the illite interlayer (Jeong et al., 2004), the proportion of the illitic component of ISCMs was lower in the Tenerife Saharan dust $(\mathrm{K}=1.51 \%$ on average) than in Asian dust $(\mathrm{K}=2.2 \%)$.

The internal structures of the Saharan dust particles are basically similar to those of Asian dust particles, which were grouped into three types: type I, large non-clay grains with clay coatings; type II, clay-rich agglomerates with inclusions of non-clay mineral grains; and type III, large platy minerals with clay coatings. The dust particles shown in Figs. 2, 5, and 7 have type II internal structures. Those shown in Figs. 3 and 4 have type I and type III internal structures, respectively. Irregular pores of varying sizes were reported in the interiors of Asian dust particles (Jeong and Nousiainen, 2014). Recent modeling of the optical properties of mineral dust showed that the internal pores of dust particles affect these properties (Kemppinen et al., 2015). Pores in the interiors of Tenerife Saharan dust particles, however, were rather scarce and small (Figs. 2b, 3c, and 5c; Supplement Fig. S2). The fine sizes of particles analyzed in this study may explain these findings. No particle observed by SEM exceeded $10 \mu \mathrm{m}$ (most were $<5 \mu \mathrm{m}$ ), as large particles were rare in the probed dust event. We cannot exclude the possibility that coarse particles have larger pores due to increased heterogeneity from the mixing of different mineral species, grain sizes, and surface properties. TEM analyses of additional dust samples, particularly those containing coarser particles, are required.

\subsection{Implications for dust optical properties and micronutrient transport}

In most applications, the dust particle optical properties are still based on the assumption of particle homogeneity (Nousiainen and Kandler, 2015; Kahnert et al., 2016). Based on the analysis of particle interiors of Asian dust by Jeong and Nousiainen (2014), Kemppinen et al. (2015) assessed the impacts of various types of observed inhomogeneity on the dust particles' optical properties. Their conclusion was clear: dust particles exhibit many types of inhomogeneity whose impacts on the optical properties cannot be accurately mimicked by homogeneous particle models. The impact of iron oxides in particular, whether present in isolated grains or mixed within the clay coating, could not be properly accounted for by any tested means of making the whole particles homogeneous. In addition, the presence of internal cavities led to impacts on optical properties that were challenging to mimic with homogenized particles.

The problem with iron oxides is that, at solar shortwave frequencies, their complex refractive indices differ substantially from those minerals that make most of the particle volume: the real part of refractive index can be easily a factor of 2 larger for the iron oxide, and the imaginary part tends to be larger by many orders of magnitude. A high imaginary part means that the particle interior is strongly absorbing, but the high real part may make it difficult for the radiation to penetrate through the particle surface to be absorbed. However, when a mixing formula is applied to average the refrac- 
tive indices of the component materials, the typically small amounts of iron oxides are not sufficient to increase the real part of the refractive index much above that of the dominating minerals; however, the extremely large difference in the imaginary parts makes the whole particle interior much more absorptive. As a result, the homogenized particle will absorb light much more efficiently than either an external mixture or a model where the iron oxide grain would be present as an inclusion in a dust particle. The mixing of constituent minerals into a single, effective refractive index for model dust particles will thus lead to too much absorption and too low a single-scattering albedo.

Saharan dust was found to exhibit many types of inhomogeneity also present in Asian dust. Therefore, it appears plausible that the using homogeneous particle models for Saharan dust would result in similar potential errors as was reported by Kemppinen et al. (2015) for the Asian dust. There are, however, some differences to note. First, Saharan dust appeared to have fewer and smaller internal pores. Second, their iron oxide content was somewhat smaller. Both of these effects alone suggest a smaller impact on the optical properties due to the inhomogeneity. However, it does not mean that the impacts could be ignored, and it is further possible that the simultaneous decrease in pores and iron oxides changes the impacts. Therefore, explicit simulations to quantify the impacts are in order, and are planned for in the future.

Saharan dust is a carrier of inorganic nutrients to remote ecosystems. Iron is an element limiting phytoplankton growth in remote ocean ecosystems. The modeling of iron supply to global oceans should include mineral compositions and iron contents of constituent minerals, as highlighted in the modeling study of iron biogeochemical cycles conducted by Johnson and Meskhidze (2013). Mineral compositions and their iron chemistries were converted from world soil data for modeling (Claquin et al., 1999; Nikovic et al., 2012; Journet et al., 2014). However, a large degree of uncertainty remains regarding the mineralogical properties of fine particles in the source soils. In particular, data on the iron content of soil clay minerals are rarely available in the literature. Bulk and single-particle analyses of representative dust provide direct mineralogical information because soil particles lifted from wide source areas have been mixed thoroughly during long-range transport.

Our TEM analyses also revealed the mineralogical attributes of iron in single dust particles. Iron was partitioned into (hydr)oxides and clay minerals. The iron (hydr)oxides were goethite and hematite, with minor contributions of magnetite. Their median volume contribution to the particles was $\sim 1.5 \%$ vol. Iron-bearing silicates are clay mineral aggregates dominated by ISCMs (Table 1). The average iron content of the clay mineral aggregates in Saharan dust particles is $5 \mathrm{wt} \%$. Iron must be dissolved from clay minerals and iron (hydr)oxides before it is available for phytoplankton growth in the ocean (Rubin et al., 2011; Sholkovitz et al., 2012). The fractional $\mathrm{Fe}$ solubility $\left(\% \mathrm{Fe}_{S}\right)$ of mineral dust (Sholkovitz et al., 2012) depends on iron content, crystallinity, and the specific surface areas of iron-bearing minerals (Lasaga, 1995; Nagy, 1995). The common nano-sized grains of ISCMs and iron (hydr)oxides with high specific surface areas and low crystallinity in the dust particles may enhance iron bioavailability (Baker and Jickells, 2006).

\section{Summary and conclusions}

Dust particles are composed of minerals with wide ranges of grain size and optical and chemical properties. The optical properties related to radiative forcing and remote sensing could be calculated optimally based on realistic mineralogical, morphological, and structural models of dust particles. Analysis of micronutrient delivery to remote oceans should consider the forms of the elements in the dust particles. TEM analysis of cross sections of dust particles, aided by EDXS, revealed the details of the internal mineralogical, structural, and morphological properties of fine Saharan dust particles. Saharan dust shares many properties with Asian dust, such as internal structure, mineral composition, and ISCM chemistry, but it differs slightly in its higher clay content, fewer pores, higher kaolinite content, and higher smectitic component in ISCMs. The overall 3-D shapes of the dust particles were roughly ellipsoidal, with widely varying axial ratios. We emphasize, however, that this does not necessarily mean that their optical properties would match with those of corresponding ellipsoids. Rather, more likely, they do not (Lindqvist et al., 2014). Submicron grains of iron (hydr)oxides, mostly goethite and hematite, were commonly dispersed throughout the clay medium. Their median volume $\%$ was estimated at $\sim 1.5 \%$. Submicron- to nano-sized grains of ISCMs and iron (hydr)oxides would enhance the release of inorganic nutrients to ecosystems. These data on the mineralogical properties and structures of individual dust particles provide a basis for modeling optical properties of Saharan dust. However, we could not probe the interiors of coarse $(>10 \mu \mathrm{m})$ dust particles due to their low abundance in the probed dust plume and the technical difficulty of preparing large cross sections. Description of the general properties of single particles can be completed with coarse particle data from further investigations.

\section{The Supplement related to this article is available online at doi:10.5194/acp-16-12397-2016-supplement.}

Acknowledgements. This study was funded by the National Research Foundation of Korea grant NRF-2011-0028597 to Gi Young Jeong. Konrad Kandler greatly acknowledges support from the German Research Foundation (DFG, grants KA 2280/2 and FOR 539 SAMUM). 
Edited by: H. Saathoff

Reviewed by: K. Deboult and L. Shao

\section{References}

Anderson, J. R., Buseck, P. R., Patterson, T. L., and Arimoto, R.: Characterization of the Bermuda tropospheric aerosol by combined individual-particle and bulk-aerosol analysis, Atmos. Environ., 30, 319-338, 1996.

Arimoto, R., Zhang, X. Y., Huebert, B. J., Kang, C. H., Savoie, D. L., Prospero, J. M., Sage, S. K., Schoesslin, C. A., Khing, H. M., and Oh, S. N.: Chemical composition of atmospheric aerosols from Zhenbeitai, China, and Gosan, South Korea, during ACE-Asia, J. Geophys. Res., 109, D19S04, doi:10.1029/2003JD004323, 2004.

Avila, A., Queralt-Mitjans, I., and Alacón, M.: Mineralogical composition of African dust delivered by red rains over northeastern Spain, J. Geophys. Res., 102, 21977-21996, 1997.

Baker, A. R. and Jickells, T. D.: Mineral particle size as a control on aerosol iron solubility, Geophys. Res. Lett., 33, L17608, doi:10.1029/2006GL026557, 2006.

Boyd, P. W., Watson, A. J., Law, C. S., Abraham, E. R., Trull, T., Murdoch, R., Bakker, D. C. E., Bowie, A. R., Buesseler, K. O., Chang, H., Charette, M., Croot, P., Downing, K., Frew, R., Gall, M., Hadfield, M., Hall, J., Harvey, M., Jameson, G., LaRoche, J., Liddicoat, M., Ling, R., Maldonado, M. T., McKay, R. M., Nodder, S., Pickmere, S., Pridmore, R., Rintoul, S., Safi, K., Sutton, P., Strzepek, R., Tanneberger, K., Turner, S., Waite, A., and Zeldis, J.: A mesoscale phytoplankton bloom in the polar Southern Ocean stimulated by iron fertilization, Nature, 407, 695-702, 2000.

Claquin, T., Schulz, M., and Balkanski, Y.: Modeling the mineralogy of atmospheric dust sources, J. Geophys. Res., 104, 2224322256, 1999.

Conny, J. M.: Internal composition of atmospheric dust particles from focused ion-beam scanning electeron microscopy, Environ. Sci. Technol., 47, 8575-8581, 2013.

Coude-Gaussen, G., Rognon, P., Bergametti, G., Gomes, L., Strauss, B., Gros, J. M., and Le Coustumer, M. N.: Saharan dust on Fuerteventura Island (Canaries): Chemical and mineralogical characteristics, air mass trajectories, and probable sources, J. Geophys. Res.-Atmos., 92, 9753-9771, 1987.

Cwiertny, D. M., Young, M. A., and Grassian, V. H.: Chemistry and photochemistry of mineral dust aerosol, Annu. Rev. Phys. Chem., 59, 27-51, 2008.

Deboudt, K., Gloter, A., Mussi, A., and Flament, P.: Red-ox speciation and mixing state of iron in individual African dust particles, J. Geophys. Res., 117, D12307, doi:10.1029/2011JD017298, 2012.

Dentener, F. J., Carmichael, G. R., Zhang, Y., Lelieveld, J., and Crutzen, P. J.: Role of mineral aerosol as a reactive surface in the global troposphere, J. Geophys. Res., 101, 22869-22889, 1996.

Dubovik, O., Sinyuk, A., Lapyonok, T., Holben, B. N., Mishchenko, M., Yang, P., Eck, T. F., Volten, H., Munoz, O., Veihelmann, B., van der Zande, W. J., Leon, J. F., Sorokin, M., and Slutsker, I.: Application of spheroid models to account for aerosol particle nonsphericity in remote sensing of desert dust, J. Geophys. Res.Atmos., 111, D11208, doi:10.1029/2005JD006619, 2006.

Falkovich, A. H., Ganor, E., Levin, Z., Formenti, P., and Rudich, Y.: Chemical and mineralogical analysis of individual mineral dust particles, J. Geophys. Res.-Atmos., 106, 18029-18036, 2001.

Formenti, P., Schütz, L., Balkanski, Y., Desboeufs, K., Ebert, M., Kandler, K., Petzold, A., Scheuvens, D., Weinbruch, S., and Zhang, D.: Recent progress in understanding physical and chemical properties of African and Asian mineral dust, Atmos. Chem. Phys., 11, 8231-8256, doi:10.5194/acp-11-8231-2011, 2011.

Freedman, M. A.: Potential sites for ice nucleation on aluminosilicate clay minerals and related materials, J. Phys. Chem. Lett., 6, 3850-3858, 2015.

Gao, Y., Anderson, J. R., and Hua, X.: Dust characteristics over the North Pacific observed through shipboard measurements during the ACE-Asia experiment, Atmos. Environ., 41, 7907-7922, 2007.

Glaccum, R. A. and Prospero, J. M.: Saharan aerosols over the tropical north Atlantic - Mineralogy, Mar. Geol., 37, 295-321, 1980.

Jeong, G. Y.: The dependence of localized crystallization of halloysite and kaolinite on primary minerals in the weathering profile of granite, Clays Clay Miner., 48, 196-203, 2000.

Jeong, G. Y.: Bulk and single-particle mineralogy of Asian dust and a comparison with its source soils, J. Geophys. Res.-Atmos., 113, D02208, doi:10.1029/2007JD008606, 2008.

Jeong, G. Y. and Achterberg, E. P.: Chemistry and mineralogy of clay minerals in Asian and Saharan dusts and the implications for iron supply to the oceans, Atmos. Chem. Phys., 14, 1241512428, doi:10.5194/acp-14-12415-2014, 2014.

Jeong, G. Y. and Nousiainen, T.: TEM analysis of the internal structures and mineralogy of Asian dust particles and the implications for optical modeling, Atmos. Chem. Phys., 14, 7233-7254, doi:10.5194/acp-14-7233-2014, 2014.

Jeong, G. Y., Yoon, H. I., and Lee, S. Y.: Chemistry and microstructures of clay particles in smectite-rich shelf sediments, South Shetland Islands, Antarctica, Mar. Geol., 209, 19-30, 2004.

Jeong, G. Y., Kim, J. Y., Seo, J., Kim, G. M., Jin, H. C., and Chun, Y.: Long-range transport of giant particles in Asian dust identified by physical, mineralogical, and meteorological analysis, Atmos. Chem. Phys., 14, 505-521, doi:10.5194/acp-14-505-2014, 2014.

Jickells, T. D., An, Z. S., Andersen, K. K., Baker, A. R., Bergametti, G., Brooks, N., Cao, J. J., Boyd, P. W., Duce, R. A., Hunter, K. A., Kawahata, H., Kubilay, N., laRoche, J., Liss, P. S., Mahowald, N., Prospero, J. M., Ridgwell, A. J., Tegen, I., and Torres, R.: Global Iron Connections Between Desert, Dust, Ocean Biogeochemistry, and Climate, Science, 308, 67-71, 2005.

Johnson, M. S. and Meskhidze, N.: Atmospheric dissolved iron deposition to the global oceans: effects of oxalate-promoted $\mathrm{Fe}$ dissolution, photochemical redox cycling, and dust mineralogy, Geosci. Model Dev., 6, 1137-1155, doi:10.5194/gmd-6-11372013, 2013.

Journet, E., Desboeufs, K. V., Caquineau, S., and Colin, J.-L.: Mineralogy as a critical factor of dust iron solubility, Geophys. Res. Lett., 35, L07805, doi:10.1029/2007GL031589, 2008.

Journet, E., Balkanski, Y., and Harrison, S. P.: A new data set of soil mineralogy for dust-cycle modeling, Atmos. Chem. Phys., 14, 3801-3816, doi:10.5194/acp-14-3801-2014, 2014. 
Kahnert, M., Nousiainen, T., and Markkanen, J.: Morphological Models for Inhomogeneous Particles: Light scattering by aerosols, cometary dust, and living cells, Light Scattering Reviews, 11, 299-337, 2016.

Kanayama, S., Yabuki, S., Yanagisawa, F., and Motoyama, R.: The chemical and strontium isotope composition of atmospheric aerosols over Japan: the contribution of long-range-transported Asian dust (Kosa), Atmos. Environ., 36, 5159-5175, 2002.

Kandler, K., Benker, N., Bundke, U., Cuevas, E., Ebert, M., Knippertz, P., Rodríguez, S., Schütz, L., and Weinbruch, S.: Chemical composition and complex refractive index of Saharan Mineral Dust at Izaña, Tenerife (Spain) derived by electron microscopy, Atmos. Environ., 41, 8058-8074, 2007.

Kandler, K., Schütz, L., Deutscher, C., Ebert, M., Hofmann, H., Jäckel, S., Jaenicke, R., Knippertz, P., Lieke, K., Massling, A., Petzold, A., Schladitz, A., Weinzierl, B., Wiedensohler, A., Zorn, S., and Weinbruch, S.: Size distribution, mass concentration, chemical and mineralogical composition and derived optical parameters of the boundary layer aerosol at Tinfou, Morocco, during SAMUM 2006, Tellus B, 61, 32-50, 2009.

Kemppinen, O., Nousiainen, T., and Jeong, G. Y.: Effects of dust particle internal structure on light scattering, Atmos. Chem. Phys., 15, 12011-12027, doi:10.5194/acp-15-12011-2015, 2015.

Klaver, A., Formenti, P., Caquineau, S., Chevaillier, S., Ausset, P., Calzolai, G., Osborne, S., Johnson, B., Harrison, M., and Dubovik, O.: Physico-chemical and optical properties of Sahelian and Saharan mineral dust: in situ measurements during the GERBILS campaign, Q. J. Roy. Meteor. Soc., 137, 1193-1210, 2011.

Kulkarni, G. and Dobbie, S.: Ice nucleation properties of mineral dust particles: determination of onset RHi, IN active fraction, nucleation time-lag, and the effect of active sites on contact angles, Atmos. Chem. Phys., 10, 95-105, doi:10.5194/acp-10-95-2010, 2010.

Lafon, S., Sokolik, I. N., Rajot, J. L., Caquineau, S., and Gaudichet, A.: Characterization of iron oxides in mineral dust aerosols: Implications for light absorption, J. Geophys. Res., 111, D21207, doi:10.1029/2005JD007016, 2006.

Lasaga, A. C.: Fundamental approaches in describing mineral dissolution and precipitation rates, Rev. Mineral., 31, 23-86, 1995.

Laskin, A., Wietsma, T. W., Krueger, B. J., and Grassian, V. H.: Heterogeneous Chemistry of Individual Mineral Dust Particles with Nitric Acid: A Combined CCSEM/EDX, ESEM, and ICP-MS Study, J. Geophys. Res.-Atmos., 110, D10208, doi:10.1029/2004JD005206, 2005.

Lindqvist, H., Jokinen, O., Kandler, K., Scheuvens, D., and Nousiainen, T.: Single scattering by realistic, inhomogeneous mineral dust particles with stereogrammetric shapes, Atmos. Chem. Phys., 14, 143-157, doi:10.5194/acp-14-143-2014, 2014.

Mahowald, N. M., Engelstaedter, S., Luo, C., Sealy, A., Artaxo, P., Benitez-Nelson, C., Bonnet, S., Chen, Y., Chuang, P. Y., Cohen, D. D., Dulac, F., Herut, B., Johansen, A. M., Kubilay, N., Losno, R., Maenhaut, W., Paytan, A., Prospero, J. M., Shank, L. M., and Siefert, R. L.: Atmospheric iron deposition: global distribution, variability, and human perturbations, Annu. Rev. Mar. Sci., 1, 245-278, 2009

Merikallio, S., Lindqvist, H., Nousiainen, T., and Kahnert, M.: Modelling light scattering by mineral dust using spheroids: as- sessment of applicability, Atmos. Chem. Phys., 11, 5347-5363, doi:10.5194/acp-11-5347-2011, 2011.

Mishchenko, M. I., Travis, L. D., Kahn, R. A., and West, R. A.: Modeling phase functions for dustlike tropospheric aerosols using a shape mixture of randomly oriented polydisperse spheroids, J. Geophys. Res, 102, 16831-16847, 1997.

Nagy, K. L.: Dissolution and precipitation kinetics of sheet silicates, Rev. Mineral., 31, 173-273, 1995.

Nickovic, S., Vukovic, A., Vujadinovic, M., Djurdjevic, V., and Pejanovic, G.: Technical Note: High-resolution mineralogical database of dust-productive soils for atmospheric dust modeling, Atmos. Chem. Phys., 12, 845-855, doi:10.5194/acp-12-8452012, 2012.

Nousiainen, T. and Kandler, K.: Light scattering by atmospheric mineral dust particles, Light Scattering Reviews, 9, 3-52, 2015.

Nousiainen, T. and Vermeulen, K.: Comparison of measured singlescattering matrix of feldspar particles with T-matrix simulations using spheroids, J. Quant. Spectrosc. Ra., 79-80, 1031-1042, 2003.

Okada, K., Naruse, H., Tanaka, T., Nemoto, O., Iwasaka, Y., Wu, P. -M., Ono, A., Duce, R. A., Uematsu, M., Merrill, J. T., and Arao, K.: X-ray spectrometry of individual Asian dust-strom particles over the Japanese islands and the north Pacific Ocean, Atmos. Environ. A, 24, 1369-1378, 1990.

Okada, K., Heintzenberg, J., Kai, K., and Qin, Y.: Shape of atmospheric mineral particles collected in three Chinese arid-regions, Geophys. Res. Lett., 28, 3123-3126, 2001.

Ooki, A. and Uematsu, M.: Chemical interactions between mineral dust particles and acid gases during Asian dust events, J. Geophys. Res., 110, D03201, doi:10.1029/2004JD004737, 2005.

Park, M. Y. and Jeong, G. Y.: Mineralogical properties of Asian dust sampled at Deokjeok Island, Incheon, Korea in February 22, 2015, J. Min. Soc. Korea, 29, 79-87, 2016.

Reid, J. S., Jonsson, H. H., Maring, H. B., Smirnov, A., Savoie, D. L., Cliff, S. S., Reid, E. A., Livingston, J. M., Meier, M. M., Dubovik, O., and Tsay, S. C.: Comparison of size and morphological measurements of coarse mode dust particles from Africa, J. Geophys. Res., 108, 8593, doi:10.1029/2002JD002485, 2003.

Ro, C.-U., Hwang, H., Kim, H., Chun, Y., and Van Grieken, R.: Single-particle characterization of four "Asian dust" samples collected in Korea, using low-Z particle electron probe X-ray microanalysis, Environ. Sci. Technol., 39, 1409-1419, 2005.

Rubin, M., Berman-Frank, I., and Shaked, Y.: Dust- and mineral iron utilization by the marine dinitrogen-fixer Trichodesmium, Nat. Geosci., 4, 529-534, doi:10.1038/NGEO1181, 2011.

Scheuvens, D., Schütz, L., Kandler, K., Ebert, M., and Weinbruch, S.: Bulk composition of northern African dust and its source sediments - A compilation, Earth-Sci. Rev., 116, 170-194, 2013.

Seinfeld, J. H., Carmichael, G. R., Arimoto, R., Conant, W. C., Brechtel, F. J., Bates, T. S., Cahill, T. A., Clarke, A. D., Doherty, S. J., Flatau, P. J., Huebert, B. J., Kim, J., Markowicz, K. M., Quinn, P. K., Russell, L. M., Russell, P. B., Shimizu, A., Shinozuka, Y., Song, C. H., Tang, Y., Uno, I., Vogelmann, A. M., Weber, R. J., Woo, J.-H., and Zhang, X. Y.: ACE-ASIA regional climatic and atmospheric chemical effects of Asian dust and pollution, B. Am. Meteorol. Soc., 85, 367-380, 2004.

Shao, L., Li, W., Xiao, Z., and Sun, Z.: The mineralogy and possible sources of spring dust particles over Beijing, Adv. Atmos. Sci., 25, 395-403, 2008. 
Shi, Z., Shao, L., Jones, T. P., and Lu, S.: Microscopy and mineralogy of airborne particles collected during severe dust storm episodes in Beijing, China, J. Geophys. Res., 110, D01303, doi:10.1029/2004JD005073, 2005.

Sholkovitz, E. R., Sedwick, P. N., Church, T. M., Baker, A. R., and Powell, C. F.: Fractional solubility of aerosol iron: Synthesis of a global-scale data set, Geochim. Cosmochim. Ac., 89, 173-189, 2012.

Sokolik, I. N. and Toon, O. B.: Direct radiative forcing by anthropogenic airborne mineral aerosols, Nature, 381, 681-683, 1996.

Stein, A. F., Draxler, R. R., Rolph, G. D., Stunder, B. J. B., Cohen, M. D., and Ngan, F.: NOAA's HYSPLIT Atmospheric Transport and Dispersion Modeling System, B. Am. Meteorol. Soc., 96, 2059-2077, doi:10.1175/bams-d-14-00110.1, 2015.
Swap, R., Garstang, M., Greco, S., Talbot, R., and Kållberg, P.: Saharan dust in the Amazon Basin, Tellus B, 44, 133-149, 1992.

Tegen, I. and Lacis, A. A.: Modeling of particle size distribution and its influence on the radiative properties of mineral dust aerosol, J. Geophys. Res., 101, 19237-19244, 1996.

Vepraskas, M. J. and Wilson, M. A.: Soil Micromorphology: concepts, techniques, and applications, in: Methods of Soil Analysis, Part 5, edited by: Ulery, A. L. and Dress, L. R., Soil Science Society of America Book Ser. 5, 191-226, Soil Science Society of America, Madison, Wisconsin, 2008. 